\title{
TEATRO DEL SIGLO DE ORO EN INDIAS. LA "ZARZUELA" DE LA PURIFICACIÓN DE POTOSÍ (CONVENTO DE SANTA TERESA)
}

IGNACIO ARELLANO

Universidad de Navarra

1. UnA COLECCión de teXtos dRAMÁticos DEL CONVENTO de SANTA TERESA DE LA VILLA IMPERIAL DE POTOSÍ

En agosto del año 2002, en una excursión a la Villa Imperial de Potosí en el marco del III Encuentro Boliviano de Estudios Clásicos, celebrado en Sucre, visitamos el convento de Santa Teresa, en cuyo pulcro museo y biblioteca se conserva una caja con un rótulo que indicaba el contenido: piezas de teatro para las fiestas del Carmelo desde el siglo XVII al XIX. Di noticia de este hallazgo con cierto detalle en mi ponencia del Congreso «Temas del Barroco Hispánico» en Valparaíso (noviembre del 2003), publicada en el 2004', y Andrés Eichman ha editado una de estas piezas, que titulamos Coloquio de los once cielos ${ }^{2}$.

Debemos a la Madre Carmen Álvarez, Superiora del Convento, las facilidades para estudiar estas piezas manuscritas.

La colección, copiada por distintas manos y sin duda a lo largo de cierto tiempo, presenta, creo, un notable interés, pues refleja fielmente el tipo de textos que formaba parte de las celebraciones potosinas (sobre todo de $\mathrm{Na}$ vidad y la Candelaria), y supone un cierto aumento de las piezas dramáticas conocidas, principalmente auriseculares, conservadas en Hispanoamérica. En especial aumenta de manera notable los materiales de la zona de Charcas.

Muy pocos datos teníamos del teatro del Siglo de Oro en Charcas. En un artículo todavía reciente, Josep Barnadas y Ana Forenza ${ }^{3}$, antes de ofrecer algunos nuevos avances, hacen una breve panorámica, sin pretensiones

\footnotetext{
1 Ver Arellano, 2004.

${ }^{2}$ Eichman, 2003a.

${ }^{3}$ Barnadas y Forenza, 2000, p. 557.
}

Rlit, LXVII, 133 (2005), 193-209 
de exhaustividad, de los distintos aportes que vieron la luz a lo largo del siglo $\mathrm{Xx}$ :

Nadie podrá afirmar que ya hayamos llegado a conocer, ni siquiera en los rasgos generales de su evolución, la historia teatral de Charcas. Simplemente, porque ni la divulgación de dos de las espectaculares fiestas potosinas, con sus explícitos componentes teatrales, la de 1608 (Hanke, 1956-1957) y la de 1663 (Moglia, 1943); ni el presentar a la atención de los investigadores lo que promete una búsqueda sistemática en los archivos potosinos (Helmer, 1960); ni, incluso, el lugar nada despreciable que el teatro tuvo en un panorama de las letras coloniales de Charcas (Gisbert, 1968, 27-66) o que Charcas ha obtenido en un panorama continental indiano (Suárez, 1981, II, 283313): nada de ello puede pasar por un panorama que documente el repertorio teatral charqueño (con la correspondiente cuota de producción local), la infraestructura material en que se apoyaba, el repertorio de elencos de actores, el abanico temático, las funciones sociales que el teatro desempeñaba en la sociedad colonial, el papel que en todo este capítulo histórico jugaron los indios y lo indígena, etc., etc. El único sector en el que acaba de aparecer una monografía sólida, basada en una amplia consulta documental, trata del teatro indígena posterior al siglo XVI y centrado en la zona orureña (Beyersdorff, 1998).

A las contribuciones mencionadas en la citada síntesis podrían añadirse otros trabajos de diversa dimensión: artículos de divulgación general como el de Maritza Wilde ${ }^{4}$, otros que abordan un fenómeno puntual, es el caso de Carlos Cordero 5 , la sección dedicada al teatro en obras que se ocupan de la literatura boliviana en su conjunto (por ejemplo Cáceres Romero ${ }^{6}$ ) o la edición de la comedia de Fray Diego de Ocaña por Teresa Gisbert ${ }^{7}$, que tiene el mérito de ser la única producida en Bolivia en todo el siglo XX. Por ahora no pretendo hacer un rastreo de textos que se ocupan de esta actividad, que se sitúa fuera de mi objeto. Lo cierto es que gran parte de los temas señalados por Barnadas y Forenza continúan inexplorados. Eich$\operatorname{mann}^{8}$ ha puntualizado también que

el repertorio conocido de obras teatrales conservadas de Charcas no es muy abultado, a pesar de su intenso cultivo en las ciudades más importantes del territorio, es decir La Plata y Potosí. El teatro fue un «componente cotidiano de la vida potosina» ${ }^{9}$, atestiguado por muchas fuentes; además, "está claro y es conocido que La Plata y $\mathrm{La} \mathrm{Paz}$ formaban circuito en las giras de las compañías teatrales por Charcas» ${ }^{10}$. [...] Pero el paradero de muchas de las obras cuya representación consta en documentos y crónicas es desconocido.

\footnotetext{
${ }^{4}$ Wilde, 1998.

5 Cordero, 2004.

${ }^{6}$ Cáceres Romero, 1990.

7 Edición de 1957.

${ }^{8}$ Eichmann, 2003b, p. 96.

9 Barnadas y Forenza, 2000, p. 558.

${ }^{10}$ Barnadas y Forenza, 2000, p. 570.
} 
La misma variedad de los géneros representados, unos cómicos, otros serios religiosos, alguna comedia hagiográfica (incompleta), y fragmentos musicales varios, etc., aumentan al valor de este repertorio del convento potosino. Con la veintena aproximada de obras dramáticas que nos ofrece casi permite triplicar el reducidísimo corpus teatral del periodo indiano ${ }^{11}$, en la construcción de un camino que todavía no es posible transitar por la falta de textos suficientes para sacar conclusiones más detalladas.

La colección de Santa Teresa puede considerarse, en el panorama descrito, un hallazgo de notable relevancia, que incluye, por otro lado, algunas piezas de intrínseco valor literario.

La colección está compuesta de los siguientes textos:

a) Siete entremeses: El pleito de los pastores, Entremés dedicado a la Verdad, Entremés del astrólogo tunante, Entremés de los compadres (dos copias, una de ellas incompleta), Entremés de los tunantes, Entremés cantado del robo de las gallinas, Entremés gracioso para la festividad de Nuestra Señora de 1799.

b) Dos coloquios, seis loas y una denominada zarzuela. En realidad todas estas piezas son de dimensión, estructura y técnica semejante, aunque ofrecen algunas variaciones curiosas. La mayoría está escrita para la fiesta de la Purificación o de la Candelaria.

c) Una serie de papeles sueltos y piezas incompletas. Estos papeles corresponden a los textos que un actor debía memorizar y tienen señalados los reclamos (palabras finales de los parlamentos anteriores) que dan pie para la entrada del parlamento de los personajes en cuestión.

Sobre las fechas de composición solamente pueden ofrecerse conjeturas muy generales. El convento se fundó en 1687: alguna de las piezas como la Loa de Nuestra Señora del Carmen debe de haber sido escrita por alguna monja para el propio ámbito conventual, y es sin duda posterior a la fundación. En la colección se incluye el Entremés gracioso fechado en 1799, pero esta podría ser la fecha de la copia preparada para la fiesta de la

\footnotetext{
${ }^{11}$ En general se conocen unos pocos textos: el único accesible es el de la ya mencionada Comedia de Nuestra Señora de Guadalupe y sus milagros, de Ocaña, escrita en Potosí hacia 1600, editada por Teresa Gisbert en 1957; pueden añadirse nueve piezas de las que apenas se conocen los títulos (y excepcionalmente, alguna copia): la égloga pastoril El dios Pan de Diego Mejía de Fernangil, escrita también a principios del siglo XVII; la Comedia famosa El juramento ante Dios y Lealtad conta el amor de Jacinto Cordero, y El hijo de las batallas, del mismo autor; Los sucesos de tres horas, de Oviedo y Herrera; una loa para la entrada del virrey Morcillo, de Juan de la Torre; una pieza muy breve de Salvador de Vega: Efectos que causa en el alma al que recibe el Santísimo Sacramento; la Loa que al mérito del Brigadier don Sebastián de Segurola compuso por vía de epitalamio don Pedro Nolasco Crespo, de fines del XVIII; Siripo, de Labardén, y una comedia incaica escrita en verso titulada El poder de la fortuna (ver Gisbert, 1968 y Cáceres Romero, 1990, pp. 144-78).
} 
Candelaria de ese año, sin que el texto necesariamente sea de ese momento. La Loa para el nacimiento del Niño Dios, escrita por el devoto Mariano Fernández, sí podemos situarla en la fecha que indica en el título, de 1830.

Sea como fuere la mayor parte de los textos pertenecen por su estética al Siglo de Oro, extendido en Hispanoamérica durante el siglo XVIII.

De las autorías se puede señalar tan pocos detalles como de las fechas. Algunos textos religiosos, como se ha dicho, podrían atribuirse a las mismas monjas del convento que no consideraron necesario especificar el nombre de la escritora.

Los copistas, igualmente sin identificar, son siempre locales, como evidencian fenómenos reflejados en las copias: seseo, ceceo, fenómenos fonéticos de influencia quechua, etc.

No es posible, por tanto, desentrañar ni las fechas ni los autores de tales piezas a menos que surjan nuevos datos o documentos (cosa difícil): en un conjunto típicamente anónimo, del cual solo pueden indentificarse algunos restos: uno de los manuscritos es copia incompleta del entremés de El astrólogo tunante de Bances Candamo (1662-1704), que puede haberse hecho en cualquier momento, lo mismo que la copia del papel de Margarita que pertenece a la comedia de Felipe Godínez (muerto en 1647) O el fraile ha de ser ladrón o el ladrón ha de ser fraile.

No hay modo de afinar más estas cuestiones.

\section{Los teXtos Religiosos Y LA «ZARZUELA» DE LA PURIFICACIÓN}

Los textos religiosos ${ }^{12}$ pertenecen a dos ciclos principales que responden a los dos momentos de celebraciones en que se inserta su representación teatral: la Navidad y la fiesta de la Purificación o Virgen de la Candelaria.

Abre la serie la «Sarzuela» dedicada a la Purificación, que es el texto que me ocupa en esta oportunidad. Aunque se denomina zarzuela es una especie de loa de 285 versos, en su mayoría octosílabos, con alternancia de rima asonante y consonante y pasajes cantados por la música y otros hablados. Los personajes son alegorías: el Placer, el Mundo, el Amor, el Regocijo, la Intercesión y la Alegría.

La acotación primera muestra preocupación por el lucimiento y simbolismo del vestuario:

$$
\begin{aligned}
& \text { Se advierte que las personas han de estar vestidas, el Plaser de gala, con ropa } \\
& \text { de color, y las demás de blanco, hombres y mujeres, y con alas y guirnaldas } \\
& \text { blancas, para que demuestren que son divinas, exceptuando el Plaser, que es }
\end{aligned}
$$

12 Varios entremeses se sitúan también en la Navidad y la Candelaria. Se trata sin duda de adaptaciones a la ocasión concreta de las representaciones. 
humano, y todos han de sacar una tarjeta en la mano en que estará puesta la primera letra de su nombre..

El comienzo es una cita del himno mariano «Ave, maris stella» en latín, al que sigue una relación del Placer en que repasa distintos episodios de la vida de la Virgen y pone de relieve sus cualidades, como la Inmaculada Concepción. El núcleo de la pieza es un juego escénico de ingenio en el que los personajes se colocan en línea con una tarjeta en las manos que lleva la primera letra de su nombre, de modo que todos juntos componen «MARÍA» (Mundo-Amor-Regocijo-Intercesión-Alegría). Sobra la letra P del Placer, pero colocándola al inicio se interpreta «Purificada María». Cada personaje explica el sentido de su letra, técnica de la glosa ingeniosa que estructura el elogio a María:

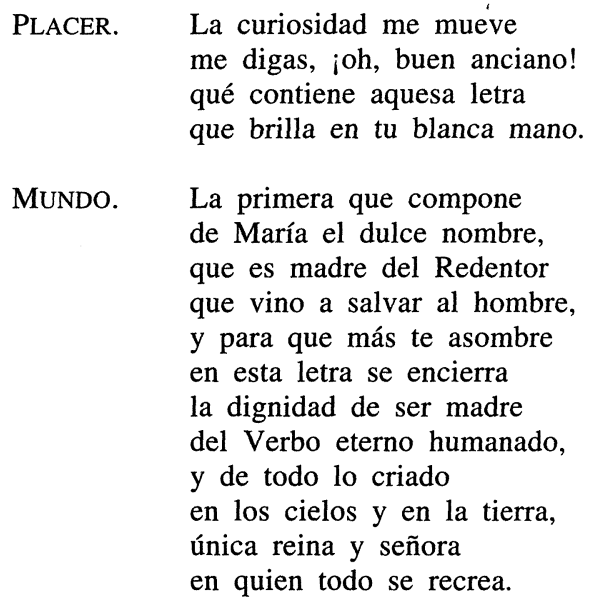

Acaba la zarzuela con la paráfrasis del Ave María con que los personajes rinden veneración a la Virgen. Algunos personajes están pensados para que los interpreten las monjas, o al menos para dar entrada a una participación de la comunidad monacal en el desenlace, según revelan los últimos versos:

$$
\begin{aligned}
& \text {-Y en fin, recibe, Señora } \\
& \text { este obsequio, que rendidas... } \\
& \text { - Hoy a tus pies te ofrecemos } \\
& \text { con humildad vuestras hijas. }
\end{aligned}
$$

De la segunda pieza, el Coloquio de la Purificación de Nuestra Señora en que hablan los once cielos, ha hecho una edición anotada Eichmann ${ }^{13}$,

\footnotetext{
${ }^{13}$ Eichmann, 2003. La cita siguiente en p. 110. Remito a este artículo de Eichman para mayores precisiones sobre este coloquio.
} 
que también se ha ocupado de la organización alegórica de este debate en que los once cielos u orbes celestes defienden su preeminencia en los festejos de la Candelaria.

La importante fiesta de la Purificación de la Virgen recuerda el episodio en que la Sagrada familia se dirige al Templo de Jerusalén con Jesús niño, para hacer las ofrendas y ceremonias prescritas en la ley de Moisés, que toda madre que daba a luz a su primogénito debía cumplir para purificarse. La Virgen no estaba realmente obligada a esta purificación, innecesaria para su caso excepcional de concepción y parto virginales, pero cumple ejemplarmente con la ley. Así lo explica la pieza que edito:

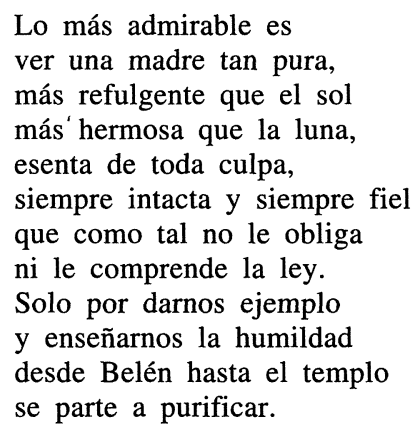

Cita Eichmann un texto interesante de Ramos Gavilán que cumple aducir aquí:

Cristo y su Santísima Madre quisieron sujetarse a la ley para enseñarnos que la obediencia es la medicina verdadera para alcanzar la salud del alma. La desobediencia fue la puerta por donde entró el mal de nuestra miseria, y así Cristo, para que nos veamos libres de las manos de aquel Dragón infernal, nos enseña, juntamente con su Madre Santísima a obedecer y guardar la ley de Dios. Mostró la Virgen en aqueste hecho heroico actos profundísimos de humildad, pobreza y obediencia, y de singular devoción y reverencia, pidiendo al Sacerdote rogase a Dios por ella. Mostró juntamente grande amor a la pureza y limpieza, pues con estar limpia de toda culpa, gustó y quiso purificarse, para enseñarnos que el camino verdadero de agradar a Dios es el de la limpieza ${ }^{14}$.

La fiesta litúrgica de la Purificación se conoce también como la Candelaria, por el simbolismo de la procesión de las candelas, y su bendición. A mediados del siglo $\mathrm{V}$ esta fiesta se conocía como La Candelaria o Fiesta de las Luces. Hasta el siglo VI se celebraba a los cuarenta días de la Epifanía, el 15 de febrero. Después se fija en el 2 de febrero, a los cuarenta días de la Navidad, que es cuando la Virgen presentó a Jesús en el Tem-

${ }^{14}$ Historia del célebre santuario de Nuestra Señora de Copacabana, y sus milagros, e invención de la Cruz de Carabuco, lib. III, octavo día. 
plo. De origen oriental, esta fiesta no se introdujo en la liturgia del Occidente hasta el siglo VII. Al final de este siglo ya estaba extendida en toda Roma y en casi todo Occidente.

Cuatro piezas más se añaden a las dos anteriores sobre el tema de la Purificación. En el Coloquio poético a la Purificación intervienen Simón, Ana, el ángel Gabriel, la Ley Vieja y Zorobabel, criado de Simeón y figura de gracioso. Más interesante es la Loa a la Purificación de María Santísima. El texto principal es un diálogo entre el Ángel y el Hombre que desarrolla una rica simbología mariana: Aurora, Madre de la gracia, Tálamo del Esposo, Paraíso, Torre de David, Escala de Jacob, Paloma, Vara de Jessé, etc. La Loa a la asumpción de María Santísima no se distingue esencialmente de la anterior. De hecho otra loa siguiente que se titula Loa dedicada a la Purificación de María Santísima coincide en su mayor parte con el texto de esta de la asunción. Aunque son dos fiestas diferentes, para ambas ocasiones pueden servir igualmente las loas mencionadas. Estas dos loas ${ }^{15}$ se construyen en forma de competencia o debate entre el Sol y la Luna (más la Aurora en la primera) sobre quién representa mejor a la Virgen. Cada uno glosa la simbología que le puede ser atribuida en el sentido mariano: los textos estriban, pues, en una serie de tipos o imágenes simbólicas de María, que continúa explorando la misma técnica de la Loa a la Purificación que comentaba antes.

Otras dos loas pertenecen al ciclo navideño: son la Loa dedicada al nacimiento de Cristo y la Loa para el nacimiento del Niño Dios.

Queda por fin, una última loa específicamente destinada a la exaltación de la orden del Carmelo y la Virgen del Carmen: la Loa de Nuestra Señora del Carmen. Seis personajes organizados en parejas desarrollan esta pieza: los Montes Atlas y Carmelo, los profetas Elías y Eliseo, la Virgen y Santa Teresa. La apertura plantea el debate entre Atlas y Carmelo.

El conjunto no habría de analizarse tanto en un marco de tarea evangelizadora (que a la altura de los textos ya ha sido cumplida con creces en una ciudad como Potosí) sino en el marco de las celebraciones religiosas y festivas que tenían su paralelo en otros lugares de la cultura hispánica. Salvo alguna pieza específica como la Loa de Nuestra Señora del Carmen tampoco cabe advertir una posible «variante» carmelitana en estos textos.

Mientras procedemos a la edición del conjunto completo, sirva de avance esta edición de la denominada zarzuela (estructuralmente se trata de una loa como las restantes), para la que sigo el manuscrito anónimo del convento de Santa Teresa aplicando los criterios de edición del GRISO ${ }^{16}$.

${ }^{15}$ En la primera hablan la Aurora, el Sol, la Luna y la Música; en lą segunda Apolo (Sol), Diana (Luna) y la Música.

${ }^{16}$ Pueden verse en http://griso.cti.unav.es/docs/lineas/normas/principal.html 


\title{
SARZUELA $^{17}$ DEDICADA A LA PURIFICACIÓN DE MARÍA SANTÍSIMA
}

Personas que hablan en ella

\author{
El Plaser \\ El MUNDO \\ EL AMOR \\ EL REGOCIJO ${ }^{18}$ \\ LA INTERSECIÓN ${ }^{19}$ \\ LA Alegría \\ Múcica
}

Se advierte que las personas han de estar vestidas, el Plaser de galán con ropa de color, y las demás de blanco, hombres y mujeres, con alas y guirnaldas blancas, para que demuestren que son divinas (eseptuando el Plaser, que es humano) y todos han de sacar una tarjeta en la mano en que estará puesta la primera letra de su nombre. Sale el Plaser concluido el verso y acabando la primera relación se retira a un lado para que los demás, conforme van saliendo, se vayan poniendo en orden a formar el "María», y a su tiempo se coloca el Plaser a la cabesa y se completa el reglón.

MÚCICA

Ave maris Estela ${ }^{20}$,

Dei mater alma

atque semper virgo,

felis celi porta.

(Sale el Plaser $y$ dise)

[PlACER] Hoy los montes encumbrados

las flores, aves y fuentes,

$\mathrm{y}$ todas las criaturas

vengan devotos y humildes

y los coros de los ángeles ${ }^{21}$,

${ }^{17}$ El copista o el autor, o ambos, muestran fenómenos de seseo y ceceo o hipercorrección. Los conservo como rasgos de lengua local, lo mismo que otras grafías que muestran simplificaciones o fenónemos fonéticos peculiares de la zona.

${ }^{18}$ Aquí la grafía refleja la interdental. En la mayoría de las ocasiones refleja el seseo que sería, sin duda, la norma de este amanuense, como la posible hipercorrección en «Múcica», etc.

${ }^{19}$ Entiéndase 'intercesión', con metạ́tesis.

20 vv. 1-4 Cita del conocido himno mariano «Ave maris stella, / Dei mater alma, / atque semper virgo, / felix caeli porta».

${ }^{21}$ vv. 9-11 ángeles, arcángeles, querubines, tronos, dominaciones: distintas clases de las nueve jerarquías angélicas. Bastará al curioso lector ver VII, cap. 5 «De angelis» en las Etimologías isidorianas, sobre los atributos y características de estas nueve jerar- 
arcángeles, querubines, vengan festivos $\mathrm{y}$ alegres [a] ayudarme a selebrar las grandesas de María, que para madre de Dios desde $a b$ eterno elegida es virgen imaculada ${ }^{22}$, es pura y limpia sin mella, es del Señor muy amada, María, divina estrella, de cuyo vientre ha nacido el divino Redentor para remedio del hombre obligado del amor, pues tomando carne humana de nuestra naturalesa, escogió para su cuna con humildad y pobresa el establo de Belén donde con tiernos amores le alaban millares de ángeles y le adoran los pastores. También le adoran tres reyes que vienen de lejas tierras ${ }^{23}$ impulsados del amor

quías angélicas, a saber, ángeles, arcángeles, tronos, dominaciones, virtudes, principados, potestades, querubines y serafines. Los querubines son las más elevadas. San Isidoro, Etimologías, VII, 5, 22 comenta a propósito de los querubines: «Cherubin autem et ipsi sublimes caelorum potestates et angelica ministeria perhibentur, qui ex hebreo in linguam nostram interpretantur scientiae multitudo. Sunt enim sublimiora agmina angelorum, qui pro eo, quod vicinius positi divina scientia ceteris amplius pleni sunt, Cherubin id est plenitudo scientiae apellantur». Para el mismo San Isidoro, Etimologías, VII, 5, 21, los tronos se llaman así «porque ante ellos está sentado el Creador y a través de ellos se transmiten sus órdenes». Etc.

${ }^{22}$ v. 17 virgen inmaculada: alusión a la Inmaculada Concepción de la Virgen. Dios liberó a María del pecado original a causa de los méritos de Cristo, con vistas a su maternidad. Fue el franciscano Juan Duns Scoto (1270-1308) quien formuló esta doctrina, llamada de la redención preservativa, sigiendo a su maestro Guillermo de Ware: fue conveniente (por su divina maternidad) que la Virgen María fuera inmune del pecado; pudo tener (por el poder de Dios) esa inmunidad; por consiguiente la tuvo. No se proclamó como dogma hasta 1854, muchos la defendían en el Siglo de Oro. Ver diferentes pronunciamientos del Magisterio de la Iglesia en Denzinger, núms. 734, 792, 1073, 1100, $1641 \ldots$ especialmente la definición de Pío IX en la bula Inneffabilis Deus (del 8 de diciembre de 1854), Denzinger, núm. 1641.

${ }^{23}$ v. 34 lejas: lejanas, forma usual en el Siglo de Oro. Comp. Calderón, El laberinto del mundo: «esotra blanca vela, / que viniendo del oriente / es el Austro el que la alienta, / sea la que ha de traer, / si doy crédito a las ciencias, / que han antevisto esta dicha / el trigo de lejas tierras» (Obras completas. Autos, p. 1561). 
guiados por una estrella,

y llenos de regosijo

reciben su bendición

ofreciéndole tres dones

que trajo su devoción.

Todo es júbilos y gosos, prodigios y maravillas,

pues hemos llegado a ver

las profecías cumplidas.

Lo más admirable es

ver una madre tan pura,

más refulgente que el sol

más hermosa que la luna,

esenta de toda culpa,

siempre intacta y siempre fiel

que como'tal no le obliga

ni le comprende la ley.

Solo por darnos ejemplo ${ }^{24}$

y enseñarnos la humildad

desde Belén hasta el templo

se parte a purificar,

donde el sumo saserdote

recibe el infante tierno

y le ofrese en sacrificio

su propio hijo al Padre eterno,

60

$y$ arrebatado del goso

el santo viejo Simeón

con lágrimas en los ojos

como a su Dios le adoró,

publicando entre sollosos

que aquese divino niño

era aquel tan deceado

el Mecías prometido y que por salvar al hombre quiso bajar desde el cielo

y tomando carne humana

con su muerte redimirlo.

De igual modo prorrumpió aquella insigne viuda Ana, anunciándole a la madre

la aflicción que le esperaba.

Pero viendo que la causa

era de tanto valor

se trocó la pena en goso

por amor al pecador.

${ }^{24}$ vv. 53 y ss. Sigue detalles de la presentación de Jesús en el Templo, según el relato evangélico. Ver San Lucas, 2. 
Yo, como soy el Plaser, a quien toca selebrar un misterio que nos trae tan grande felicidad, no quiero desperdiciar ni malograr un momento de festejar este día lleno de amor y contento.

(Canta la Múcica)

[Música] Cielo y tierra en general con alegre melodía alaben siempre a María como a reina selestial.

(Sigue el Plaser).

Pero ¿qué múcica es esta? Esas voses me recrean, pero $^{25}$ siendo yo el Plaser ¿cómo pues sin mí se alegran? Quiero ver en lo que paran.

(Sale el Mundo y dise)

[Mundo] El Mundo lleno de goso, supuesto que por María hoy su libertad consigue, quiere ensalsar este día y como la letra mía es la primera que empiesa ${ }^{26}$ a publicar la grandesa de la madre más querida, que es María, pura y limpia y $\sin$ mancha con su vida...

Plaser

La curiosidad me mueve me digas, joh, buen anciano! qué contiene aquesa letra

Mundo que brilla en tu blanca mano.

de María el dulse nombre que es madre del Redentor que vino a salvar al hombre, y para que más te asombre en esta letra se encierra

\footnotetext{
${ }^{25}$ Encima de «pero» se trazan luego dos letras «y q», como si fuera a cambiar alguna lectura que no acaba de completar; parece mejor el texto que transcribo.

${ }^{26}$ v. 103 la primera: la letra M, del Mundo, es la inicial de Madre y de María.
} 
la dignidad de ser madre del Verbo Eterno humanado, y de todo lo criado en los cielos y en la tierra única reina y señora ${ }^{27}$ en quien todo se recrea.

(Sale el Amor y dise)

[AMOR] Contento sale el Amor por traer la letra segunda del nombre de aquella que es del cielo y tierra señora, tan selebrada en la gloria pues se deleitan los ángeles repitiendo por instantes, con humildad y ternura, nombre que colma de bienes al que su favor implora.

Plaser Decidme, joven gallardo que tan alegre te asomas, ¿por qué causa es tan laudable esa letra que blasonas?

AMOR

Por estar sifrado en ella el amor de aquella madre

${ }^{27}$ v. 122 reina: «La devoción popular invoca a María como Reina. El Concilio, después de recordar la asunción de la Virgen "en cuerpo y alma a la gloriadel cielo", explica que fue "elevada [...] por el Señor como Reina del universo, para ser conformada más plenamente a su Hijo, Señor de los señores (cf. Ap 19,16) y vencedor del pecado y de la muerte" (Lumen gentium, 59). En efecto, a partir del siglo V, casi en el mismo período en que el concilio de Éfeso la proclama "Madre de Dios", se empieza a atribuir a María el título de Reina. El pueblo cristiano, con este reconocimiento ulterior de su excelsa dignidad, quiere ponerla por encima de todas las criaturas, exaltando su función y su importancia.en la vida de cada persona y de todo el mundo. [...] declarará [...] san Juan Damasceno, que atribuye a María el título de "Soberana": "Cuando se convirtió en madre del Creador, llegó a ser verdaderamente la soberana de todas las criaturas" (De fide orthodoxa) [...] Mi venerado predecesor Pío XII en la encíclica Ad coeli Reginam, a la que se refiere el texto de la constitución Lumen gentium, indica como fundamento de la realeza de María, además de su maternidad, su cooperación en la obra de la redención. La encíclica recuerda el texto litúrgico: "Santa María, Reina del cielo y Soberana del mundo, sufría junto a la cruz de nuestro Señor Jesucristo" [...] Establece, además, una analogía entre María y Cristo, que nos ayuda a comprender el significado de la realeza de la Virgen. Cristo es rey no sólo porque es Hijo de Dios, sino también porque es Redentor. María es reina no sólo porque es Madre de Dios, sino también porque, asociada como nueva Eva al nuevo Adán, cooperó en la obra de la redención del género humano [...] Citando la bula Ineffabilis Deus, de Pío IX, el Sumo Pontífice Pío XII pone de relieve esta dimensión materna de la realeza de la Virgen» (Catequesis de S.S. Juan Pablo II, Audiencia general de los miércoles. 23 de julio de 1997). 
que ante los ojos de Dios

$\mathrm{y}$ es digna de que se alabe con devoción y fervor

porque es sentro del amor y como tan dulse y suave

cautiva los corazones

$\mathrm{y}$ atrae las voluntades.

(Sale el Regosijo y dise)

[REgocIJo] Como soy el regosijo vengo de contentos lleno por traer la tersera letra de aquel nombre supremo que es el terror del infierno, es el tesoro de pobres, el remedio de los hombres, de los ángeles recreo y escudo del pecador en el instante postrero.

Plaser Vos también, joven bisarro, decidme por vuestra vida la exelencia de esa letra que en tu blanca mano brilla.

REGOCIJO

El regosijo mayor de cuantos pueden haber que logran las criaturas sin poderlo mereser, porque ha querido naser de una virgen tan constante, el hijo de Dios amante que al hombre ha de redimir asión que por su grandesa solo en Dios pudo caber.

(Sale la Interseción)

[INTERSEción] Yo, que soy la interseción, salgo contenta y ufana suponiendo que mi letra debe ser la más amada: bien lo acredita la fama; por ella logran el ver cuanto quieren conseguir con la reina soberana que siendo tan poderosa de que le ruegen se agrada. 
Plaser Decidme, bella señora,

la letra que trais vos

por qué causa es tan asepta

ante los ojos de Dios.

INTERSECIÓN Porque el que quiere tener

tan benigna intersesora ${ }^{28}$,

abrasado en viva fe

con devoción y ternura,

de la gracia se asegura

y de esta suerte le obliga

a que la bondad divina

ampare a la criatura

que se acoge a la piedad

de tan digna protectora.

(Sale lá Alegría y dise)

[ALEGRía] A mí que soy la alegría, adorno de toda fiesta, justamente me ha tocado la última letra, que es esta, que por su honor y grandesa contiene dos maravillas tan exelentes y unidas que a nuestro bien se enderesan, alegría y abogada ${ }^{29}$ en la divina presencia.

Plaser ¡Válgame Dios, qué grandesas, qué multitud de exelencias y maravillas se encierran en aquestas cinco letras! Decidme cuál es la causa y el misterio que selebran,

\footnotetext{
${ }^{28}$ v. 187 intersesora: la mediación de María, intercesora de todas las gracias, es doctrina católica corriente. Ya en época patrística se llamó medianera a María: «post mediatorem mediatrix totius mundi» («después del Mediador, eres medianera de todo el universo», Oratio IV ad Deiparam, oración atribuida a San Efrén: Ott, 1986, p. 331); San Germán de Constantinopla: «Nadie consigue la salvación si no es por ti, oh Santísima... A nadie se le concede un don de gracia si no es por ti, oh Castísima» (Ott, 1986, p. 335). El título de medianera se le atribuye en documentos oficiales de la Iglesia, como la bula Ineffabilis, de Pío IX, encíclicas sobre el rosario Adiutricem y Fidentem (Denzinger, núm. 1940 a), de León XIII; en la encíclica Ad diem illum de Pío X...; León XIII, encíclica Octobri mense: «De aquel inmenso tesoro de todas clases de gracias que el Señor nos trajo, Dios ha dispuesto que no se nos conceda ninguna si no es por medio de María» (Denzinger, núm. 1940 a), etc. El título se acogió favorablemente en la liturgia, al introducirse la festividad de la Bienaventurada Virgen María, medianera de todas las gracias (en 1921)

${ }^{29}$ v. 204 abogada: como se recuerda en la Salve, la Virgen es «abogada nuestra».
} 
cómo siendo yo el plaser sin mí gustosos se alegran.

ALEGRÍA

Advierte, humano plaser, que estas letras son divinas; nosotros las exelencias en su virtud contenidas, porque de ellas se compone aquel soberano nombre que en el cielo fue formado para consuelo del hombre, y porque mejor lo entiendas llega y ve qué dise en ellas.

Plaser Ya veo que en ellas dise...

MUNDO

Plaser

AMOR

REGOCIJO

¿Qué es lo que dise?

María.

Esta virgen nos obliga

y exige la devoción

para festejar el día de su purificación.

Este misterio tan santo reverentes festejamos y como es cosa divina divinos lo selebramos.

Plaser Pues para que esté completa una expreción tan exelsa, aún falta la letra $P$ conque este misterio empiesa: poniendo en abreviatura al principio la $\mathrm{P}$ mía completo el reglón se lea «Purificada María».

(Se pone el Plaser a la cabesa)

INTERSECIón Por cierto, Plaser humano, dichoso vienes a ser, supuesto que con nosotros has llegado a competir.

Alegría

Ya que estamos reunidos digamos con alegría puestos todos de rodillas alabansas a María.

(Se hincan todos)

Plaser Dios te salve María ${ }^{30}$ 
toda llena de gracia,

la tersera persona ${ }^{31}$

te cubre con sus alas.

MUNDO

El Señor es contigo pura, divina infanta,

pues le agradaste tanto

que a tus entrañas baja.

AMOR Bendita tú mil veses,

estrella trasformada,

entre cuantas mujeres

hijas de Eva se llaman.

REgocIJo

$\mathrm{Y}$ bendito es el fruto de tu vientre amoroso, Jesús, divino amante del hombre venturoso.

INTERSECIÓN Santa Virgen María, madre de Dios"amada, los cielos y la tierra vuestra grandesa alaban.

ALEGRÍA Ruega amable y benigna por nos los pecadores y que todos te sirvamos abrasados en amores.

Plaser Ahora que es tiempo, señora, de tantas calamidades ${ }^{32}$.

Mundo Pues lo podéis alcansar de la fuente de piedades.

AMOR $\quad \mathrm{Y}$ en la hora de nuestra muerte amparadnos generosa.

RegociJo Porque todos te gosemos en la patria venturosa.

INTERSECIÓN Y en fin recibe, señora, este obsequio que rendidas...

Alegría ...hoy a tus pies te ofresemos con humildad vuestras hijas ${ }^{33}$.

\section{FIN}

${ }^{31}$ v. 252 tersera persona: el Espíritu Santo, claro.

${ }^{32}$ v. 275 calamidades: ignoro si se refiere a alguna coyuntura concreta. De todos modos siempre hay calamidades suficientes para volver los ojos a Dios y pedirle consuelo.

${ }^{33}$ v. 285 hijas: la representan las mismas monjas. 


\section{BIBLIOGRAFÍA}

América y el teatro español del Siglo de Oro. Actas del II Congreso Iberoamericano de Teatro, Cádiz, Universidad, 1998.

ARellano, I., «Una colección dramática de Potosí (convento de Santa Teresa)», en Temas del barroco hispánico, ed. I. Arellano y E. Godoy, Madrid, Iberoamericana, 2004, pp. 25-51.

BARNADAS, J., y FORENZA, A., «Noticias sobre el teatro en Charcas (siglos XVI-XIX)», Anuario 2000, Sucre, Biblioteca y Archivo Nacionales de Bolivia, 2000, pp. 557-75.

BEYERSDORFF, M., Historia y drama ritual en los Andes bolivianos (siglos XVI-XX), La Paz, Plural, 1998.

CÁCeres Romero, A., Nueva Historia de la Literatura Boliviana, La Paz, Los amigos del libro, 1990.

CAlderón DE LA BARCA, P., Obras completas, III, Autos, ed. Á. Valbuena Prat, Madrid, Aguilar, 1987.

Cordero, C., «Obra de Pedro Calderón de la Barca en el Alto Perú: Los dos amantes del cielo», en Revista cultural, La Paz, Fundación cultural del Banco Central de Bolivia, 26, enero-febrero 2004, pp. 41-55.

DENZINGER, H., Enchiridion symbolorum et definitionum..., Friburgo, Herder, 1958. Manejo también la traducción española de D. Ruiz Bueno, Barcelona, Herder, 1963.

EIChmann, A., «El Coloquio de los Once Cielos. Una obra de teatro breve del Monasterio de Santa Teresa (Potosí)», Historia y Cultura (La Paz), 28-29, 2003a, pp. 95-132.

EICHMANN, A. «Es la agudeza pasto del alma; aproximación a los códigos literarios que operan en algunas obras de Charcas», en Memoria el I Encuentro Internacional "Barroco andino», 2003b, pp. 315-22.

GISBERT, T., y MESA, J. DE, Esquema de literatura virreinal en Bolivia, La Paz, UMSA, 1968.

HANKe, L., «The 1608 fiestas in Potosí», Boletín del Instituto Riva Agüero, Lima, 3, 1956-57, pp. 103-28.

Helmer, M., Apuntes sobre el teatro en la Villa Imperial de Potosí, Potosí, Universidad T. Frías, 1960.

Helmer, M., «Apuntes sobre el teatro en la Villa Imperial de Potosí», en Cantuta. Recueil d'articles, Madrid, Casa de Velázquez, 1993, pp. 345-61.

Isidoro, San, Etimologías, Madrid, BAC, 1951.

Moglia, R., «Representación escénica en Potosí», Revista de Filología Hispánica (Buenos Aires), II, 1943, pp. 166-67.

OCAÑA, D. DE, Comedia de nuestra señora de Guadalupe y sus milagros, ed., estudio preliminar y notas de T. Gisbert, La Paz, Biblioteca Paceña-Alcaldía Municipal, 1957.

OTT, L., Manual de Teología Dogmática, Barcelona, Herder, 1986.

Ramos Gavilán, A., Historia del célebre santuario de Nuestra Señora de Copacabana, y sus milagros, e invención de la Cruz de Carabuco (Lima, Gerónimo de Contreras, 1621), La Paz, Academia Boliviana de la Historia, 1976.

SuÁreZ RADILlo, C., El teatro barroco hispano-americano. Ensayo de una historia crítico-antológica, Madrid, J. Porrúa Turanzas, 1981.

WILDE, M., «Presencia del Siglo de Oro en Potosí», en América y el teatro español del Siglo de Oro. Actas del II Congreso Iberoamericano de Teatro, Cádiz, Universidad, 1998, pp. 281-87. 